\title{
COMPARISON OF HLA MISMATCH SCORING AND THE PRE-TRANSPLANT SERUM DONOR SPECIFIC ANTIBODY (DSA) LEVELS WITH HISTOMORPHOLOGY TO PREDICT THE ANTIBODY-MEDIATED REJECTION AS WELL AS THE SEVERITY OF REJECTION
}

\author{
Ashokkumar Raghupathy1, Arunkumar K², S. P. Arun Kumar ${ }^{3}$ \\ ${ }_{1}^{1}$ Assistant Professor, Department of Pathology, Sri Venkateshwaraa Medical College Hospital and Research Centre, Ariyur, \\ Pondicherry. \\ ${ }^{2}$ Consultant Urologist, RG Urology Hospitals, Chennai. \\ 3Professor, Department of Pathology, Sri Venkateshwaraa Medical College Hospital and Research Centre, Ariyur, Pondicherry.
}

\section{ABSTRACT}

\section{BACKGROUND}

Immunologic studies such as Human Leukocyte Antigen (HLA) typing and measurement of the Donor Specific Antibody (DSA) titre are more helpful to assess the long-term success of renal transplantation and in a superior graft survival. Amount of HLA mismatching and the immune response against the graft determine the success of renal transplantation and graft versus host disease. Rejection can be a humoral or T-cell mediated, but the humoral rejection is more important, as it has a very few diagnostic morphological features in the biopsy and these cases are resistant to anti-rejection therapy with a worse prognosis.

\section{MATERIALS AND METHODS}

Retrospective study conducted in the Department of Pathology, Sri Venkateshwaraa Medical College Hospital and Research Centre, Puducherry, on the renal allograft rejection biopsies/cases between January 2013 and December 2015; 50 rejection cases/biopsies were analysed in respect to the clinical, histological and their serological/immunological status (HLA typing and serum DSA level).

\section{RESULTS}

In this study, significant association was found between the antibody-mediated rejection cases as well as their severity with the level of HLA mismatch scoring (> 50 percent). Pre-transplant DSA levels were found to have no value in predicting the antibody-mediated rejection.

\section{CONCLUSION}

It is very difficult to evaluate the clinical outcome as well as the graft survival by measurement of pre-transplant Donor Specific Antibody (DSA) level alone. Pre-transplant DSA level does not predict the possibility of humoral rejection later.

\section{KEYWORDS}

Banff, HLA, DSA, Humoral Rejection, C4d.

HOW TO CITE THIS ARTICLE: Raghupathy A, Arunkumar K, Kumar SPA. Comparison of HLA mismatch scoring and the pretransplant serum donor specific antibody (DSA) levels with histomorphology to predict the antibody-mediated rejection as well as the severity of rejection. J. Evolution Med. Dent. Sci. 2016;5(89):6634-6638, DOI: 10.14260/Jemds/2016/1501

\section{BACKGROUND}

Transplantation of an allogeneic kidney stimulates the recipient's immune system to mount a response, which in the absence of substantial immunosuppression rejects the allograft. It also represents a manifestation of the immune systems function to distinguish self from non-self and reflects recognition of foreign antigens including the products of the Major Histocompatibility Complex (MHC) and minor Histocompatibility genes.1-4 It may be either MHC class I antigens (HLA-A and HLA-B) or class II antigens (HLA-DR, DP, DQ) and ABO blood group antigens. ${ }^{5}$ Panel Reactive Antibody (PRA or DSA) levels are routinely performed before kidney transplantation. It is a way of measuring the anti-HLA antibodies $6,7,8$ in the serum. A person's PRA can be anywhere

Financial or Other, Competing Interest: None.

Submission 01-10-2016, Peer Review 27-10-2016,

Acceptance 02-11-2016, Published 07-11-2016.

Corresponding Author:

Dr. Ashokkumar Raghupathy,

No. 13, Muslim Street,

Murugan Arul Hospital,

Thiruttani - 631209.

E-mail: ashokspp@gmail.com

DOI: $10.14260 /$ jemds $/ 2016 / 1501$

\section{(c) $($ ) $\ominus$}

from $0 \%$ to $99 \%$. PRA represents the percent of the anti-HLA antibodies in recipient serum against a set panel of HLA antigens $6,7,8$ and it can identify the risk of hyperacute or vascular rejection.

Large multicentric studies ${ }^{9}$ have shown that there is a significant beneficial influence of HLA matching/typing on the graft outcome. It also clearly showed the benefit of haplotype matching; zero, one and two haplotype matched primary renal grafts had three year graft survival ${ }^{9}$ of $74 \%, 80 \%$ and $85 \%$ respectively. Acute humoral rejection may be associated with appearance of donor specific antibodies that can be detected by flow cytometric assay or ELISA method. DSA levels are not correlated with histological features of humoral rejection.

In view of these observations, Banff (1997) classification was revised in $2003^{10}$ incorporating morphological criteria with supported immunological status. Morphologically, the changes are classified ${ }^{10}$ into,

1. Borderline.

2. Antibody-mediated rejection.

3. Acute/active cellular rejection.

4. Chronic/sclerosing allograft nephropathy. 
Humoral or antibody-mediated rejection manifest as any one of the following three types ${ }^{10,11}$

I - acute tubular injury.

II - neutrophils in peritubular capillaries.

III - fibrinoid necrosis of arteries.

Biopsies that meet the criteria for both AHR and ACR type I or II are considered to have both forms of rejection. C4d positive biopsies without acute inflammation, but with chronic injury (GBM duplication, arteriopathy, interstitial fibrosis and tubular atrophy) are considered to be chronic antibodymediated rejection. ${ }^{10}$ Biopsies with $\mathrm{C} 4 \mathrm{~d}$ and no pathology may be a manifestation of accommodation.

\section{MATERIALS AND METHODS}

50 rejection cases received between January 2014 and December 2015 were collected from the RG Urology Hospital, Chennai and analysed retrospectively with their pretransplant workup. Biopsy workup with immunohistochemical study was done at Sri Venkateshwaraa Medical College Hospital and Research Centre, Puducherry. All the biopsies were indicated (only rejection cases by clinically with adequate tissue) and performed for the diagnosis of graft dysfunction. Pre-transplant workup done from the Apollo Main Hospitals, Chennai and their HLA typing status, pretransplant DSA/PRA levels were collected from their serology/immunology section.

Histological sections are studied by staining with $\mathrm{H}$ and $\mathrm{E}$, PAS (Periodic acid-Schiff) and Silver (SM) stains. All the rejection cases were confirmed and subclassified by using Banff 2003 criteria.12-14 (Figure 1 to 4). C4d, a complement product of classical pathway 12 (triggered by anti-donor antibody) is used as a durable marker for predicting antibodymediated rejection. ${ }^{15,16}$ Immunostaining for C4d and CD34 was done by Labelled Streptavidin Biotin immunoperoxidase technique (LSAB) using monoclonal antibody to C4d and CD34 on serial step sections (Figure 3 and 4).

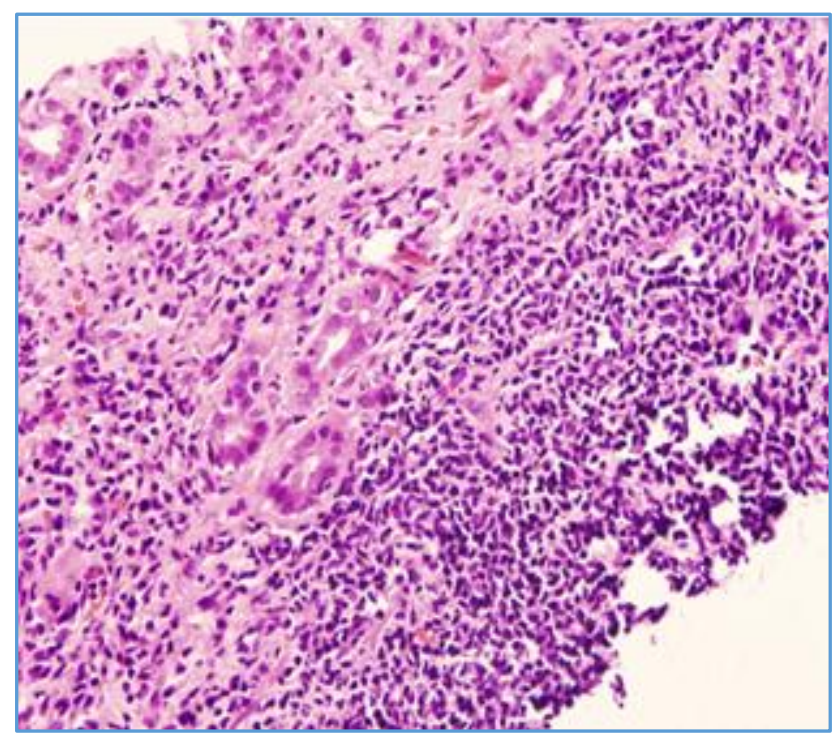

Figure 1. Tubulitis and Interstitial Inflammation

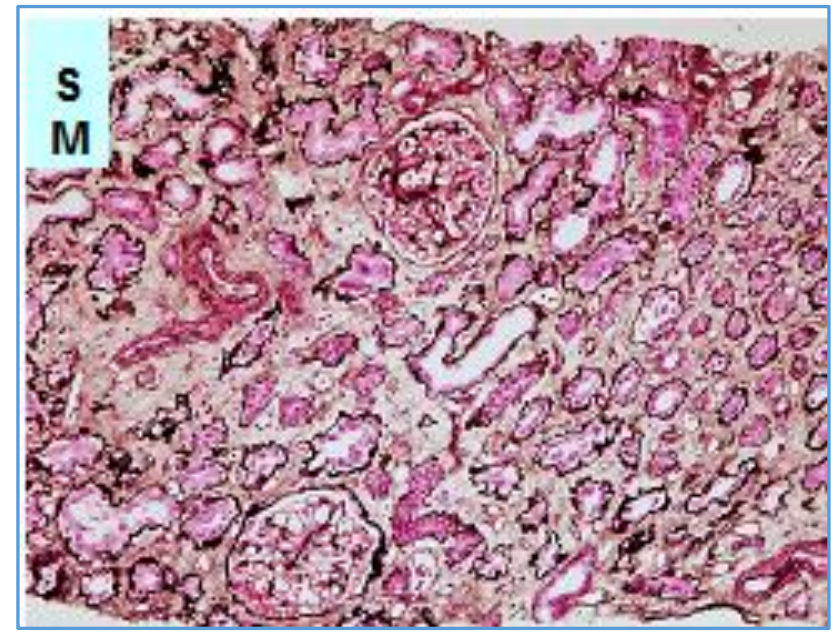

Figure 2. Tubular Atrophy and Interstitial Fibrosis

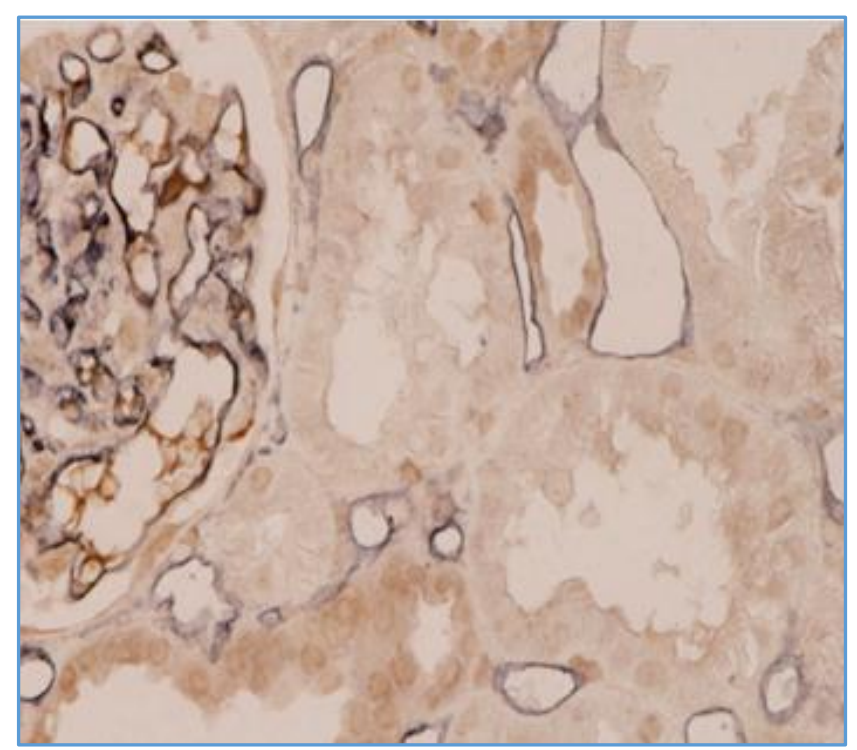

Figure 3. Positive Internal Control with C4d Negative PTC

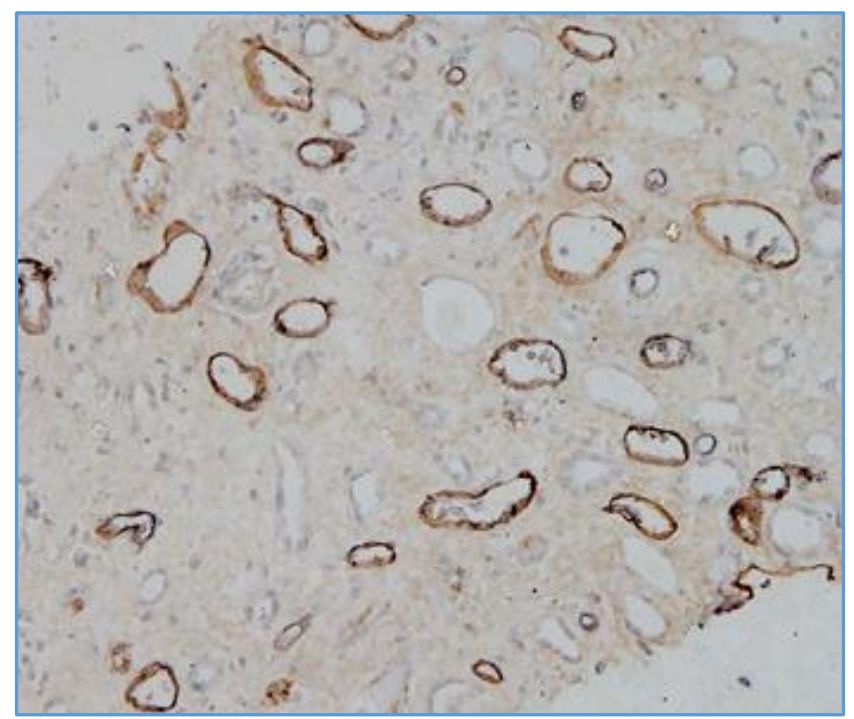

Figure 4. Diffuse C4d Positive PTC 
Lymphocytotoxicity Test (by serology) for HLA Typing17-21

The peripheral blood lymphocytes were generally used for HLA testing, because of easy availability and separation. Lymphocyte suspension for cytotoxicity test should be obtained from fresh blood samples, although $24 \mathrm{hrs}$. old blood can also yield viable cells if processed carefully. Peripheral Blood Lymphocytes (PBLs) were separated on the basis of density gradient centrifugation. The density gradient used was Lymphoprep, which has a specific density of $1.077-1.080$ at $20^{\circ} \mathrm{C}$.

\section{Procedure for HLA Typing 17-21}

HLA class antigen (A, B, C) and cross-match testing can be performed by either: Fresh peripheral blood lymphocytes separated from peripheral blood lymphocytes using nylon wool. The suspension should be adjusted to a final concentration of $2.0-2.5 \times 10^{6}$ cells $/ \mathrm{mL}$.

- The lymphocyte suspension should be $>90 \%$ pure and free of contaminants. For class I (HLA - A, B, C) typing, the cell concentration should be adjusted to $2.0-2.5 \times 10^{6}$ cells/mL.

- Trays should be thawed and brought to room temperature before use. Checked for empty wells and mark them.

- Added $1 \mu \mathrm{L}$ of lymphocyte cell suspension of each well of the test tray using a Hamilton $50 \mu \mathrm{L}$ repeating microsyringe. Care should be taken to ensure proper mixing of the sera and cells.

- Incubated the trays at room temperature $\left(20-25^{\circ} \mathrm{C}\right)$ for 30 mins.

- Added $5 \mu \mathrm{L}$ of rabbit complement (pre-screened) using a $250 \mu \mathrm{L}$ microsyringe or a multi-dispenser. Made sure that it gets mixed properly.

- Incubated the trays at room temperature $\left(20-25^{\circ} \mathrm{C}\right)$ for 1 hr.

- Added $5 \mu \mathrm{L}$ of $5 \%$ eosin dye (water soluble). Two minutes later, add $5 \mu \mathrm{L}$ of formalin ( $\mathrm{pH} 7.2-7.4$ ) to each well. Both these reagents were added using a multiple dispenser attached to a jet pipette system (Robbins Scientific Corporation, USA).

- Minimum one hour for the lymphocytes to settle down before reading the results.

- Microscopic evaluation.17-21

- Evaluation of reading the trays is done by using an inverted/phase contrast microscope. Live cells that exclude dye are small and retractile. Dead lymphocytes that uptake dyes are larger and stained dark red.

- Scoring was done by estimating the percentage of cell lyses.

- The following International scoring system is generally employed, which is also convenient. Typing trays are scored on 'subjective scales' taking into consideration the amount of 'background' (dead cells) in the negative control well.

\begin{tabular}{|c|c|c|}
\hline \multicolumn{3}{|c|}{ Score Interpretation Dead Cells (\%) } \\
\hline 1 & Negative & $0-15$ \\
\hline 2 & Doubtful Negative & $16-25$ \\
\hline 4 & Weak Positive & $26-50$ \\
\hline 6 & Positive & $51-80$ \\
\hline 8 & Strongly Positive & $81-100$ \\
\hline 0 & Not readable & \\
\hline
\end{tabular}

Estimation of Donor Specific Antibodies6-8 (DSA or PRA)

HLA antibodies can be acquired through alloimmunisation and it leads to production of HLA antibodies in approximately $33 \%$ of exposed individuals. It is estimated by ELISA method and the patient's serum is added to microwell and they are already bound with HLA antigen reacts with antibody present in the serum. Unbound antibodies are then washed away and antiIgG antibodies, substrate PNPP were added. After 30 minutes of incubation period, the reaction is stopped by a sodium hydroxide solution. The optical density of the colour that develops is measured in spectrophotometer.

Test results showing OD values equal to or greater than cut-off value are regarded as being positive result.

Calculate percentage of PRA6-8

$$
\text { PRA (\%) = } \frac{\text { \# of positive result }}{\# \text { of wells containing HLA class I antigen }} \times 100
$$

Patients are then categorised into 3 groups depending on the reactivity pattern with panel members.

$\begin{array}{ll}0-11 \% & \text { Negative. } \\ 11-50 \% & \text { Moderately sensitised. } \\ 75 \% & \text { Highly sensitised. }\end{array}$

\section{Data Analysis}

Humoral/AMR rejection cases (C4d deposition in the peritubular capillaries) and the cellular rejection biopsies as per the BANFF 2003 criteria were correlated with their HLA mismatch scoring, pre-transplant PRA levels. Fisher Exact ' $\mathrm{t}$ ' Test (Parametric Test) was done to compare the C4d deposition in different grades of rejection with HLA status/PRA levels.

\section{RESULTS}

In this study 43 cases were male, 7 female and their age groups were ranging between 17 to 51 yrs.; 39 patients (78\%) had live related donor, 10 had live unrelated and 1 had cadaver donor transplantation. End stage glomerular diseases, diabetic nephropathy ( 55 to $65 \%$ ) were the common indication for the transplantation and the other causes were chronic interstitial nephritis and adult polycystic kidney disease. Graft dysfunction was manifested from the first week of posttransplant till the 5 yrs.

\section{PRA Level}

Significant PRA levels ( $>10 \%$ ) were found in 7 patients with the mean value of $21.29 \pm 9.96$. Among these 3 ( 43 percent) patients were found to have chronic allograft nephropathy, 1 (14 percent) had Acute Cellular Rejection, 1 (14 percent) had combined acute cellular and chronic rejection and 2 (29 percent) patients were found to have no rejection in our study.

\section{HLA Mismatch Scoring (Table 1)}

In this study cases were categorised into 6, 5, 4, 3, 2, 1, 0 mismatches on the basis of their HLA disparity. HLA mismatch ' 3 ' was found in 30 cases ( 60 percent). HLA mismatch ' 4 ' was found in 3 cases ( 6 percent). Mismatch ' 5 ' was found in 10 cases ( 20 percent). HLA mismatch ' 6 ' or totally unmatched transplants were found in 7 cases (14 percent). None of them found to have complete matching $(0)$ or 1,2 mismatch. 
Based on the HLA mismatch, cases were broadly classified into two groups.

1. Less than $50 \%(<50 \%)$ HLA mismatching (HLA mismatch $3,2,1,0)$.

2. More than $50 \%$ ( $>50 \%$ ) HLA mismatching (HLA mismatch $6,5,4)$.

In this study, < 50\% HLA mismatches were found in 30 cases (60 percent). Rest of the 20 cases (40 percent) were shown $>50 \%$ HLA mismatch.

\begin{tabular}{|c|c|}
\hline HLA Mismatch Scoring & No. of Cases (n = 50) (\%) \\
\hline Less than 50\% mismatch & $30(60)$ \\
\hline More than 50\% mismatch & $20(40)$ \\
\hline \multicolumn{2}{|c|}{ Table 1 } \\
\hline
\end{tabular}

Comparison of $\mathrm{C} 4 \mathrm{~d}$ positive cases with their histological Banff ACR grades (Table 2).

\begin{tabular}{|c|c|c|}
\hline $\begin{array}{c}\text { Banff } \\
\text { (ACR) } \\
\text { Grade }\end{array}$ & $\begin{array}{c}\text { C4d Positive } \\
(\mathbf{n = 1 2 )} \mathbf{( \% )} \\
(\mathbf{p = 0 . 0 1 4 )}\end{array}$ & $\begin{array}{c}\text { C4d Negative } \\
\mathbf{( n = 3 8 )}(\mathbf{0}) \\
\mathbf{( p = 0 . 0 1 4 )}\end{array}$ \\
\hline 0 & $2(17)$ & $21(55)$ \\
\hline Borderline & $0(0)$ & $4(11)$ \\
\hline Ia & $1(8)$ & $0(0)$ \\
\hline Ib & $1(8)$ & $0(0)$ \\
\hline Ila & $3(25)$ & $6(16)$ \\
\hline IIb & $5(42)$ & $7(18)$ \\
\hline \multicolumn{3}{|c|}{ Table 2} \\
\hline
\end{tabular}

Comparison of C4d positive cases with their HLA mismatch scoring status: Association between these two variables was statistically significant (Table 3).

\begin{tabular}{|c|c|c|}
\hline $\begin{array}{c}\text { HLA } \\
\text { Mismatch } \\
\text { Score }\end{array}$ & $\begin{array}{c}\text { C4d Positive } \\
(\mathbf{n = 1 2}) \mathbf{( \% )} \\
(\mathbf{p = 0 . 0 0 7 )}\end{array}$ & $\begin{array}{c}\text { C4d Negative } \\
(\mathbf{n = 3 8 )} \mathbf{( \% )} \\
(\mathbf{p = 0 . 0 0 7 )}\end{array}$ \\
\hline $\begin{array}{c}<50 \% \\
(0,1,2,3)\end{array}$ & $3(25)$ & $27(71)$ \\
\hline $\begin{array}{c}>50 \% \\
(4,5,6)\end{array}$ & $9(75)$ & $11(29)$ \\
\hline \multicolumn{3}{|c|}{ Table 3 } \\
\hline
\end{tabular}

\section{DISCUSSION}

Statistically significant association $(p<0.05)$ was found between the grade of rejection and the $\mathrm{C} 4 \mathrm{~d}$ positivism. Higher the grade of acute cellular rejection (Banff criteria), more the chances of getting C4d deposition in PTC. C4d positive capillaries were found unevenly distributed among the various grades of chronic allograft nephropathy. The larger numbers of cases were found in grade I ( 5 cases, 42 percent) and grade 0 (4 cases, 33 percent). Only one case showed C4d deposition grade III CAN.

Comparison of $\mathrm{C} 4 \mathrm{~d}$ positive cases with PRA levels: Significant PRA levels ( $>10$ percent) were found in 7 patients with the mean value of $21.29 \pm 9.96$. None of them found to have $\mathrm{C} 4 \mathrm{~d}$ positive capillaries. $\mathrm{C} 4 \mathrm{~d}$ positive patients with the post-transplant DSA level of more than 30 percent found to have highly resistant to standard anti-rejection therapy and a greater rate of degree of graft loss. ${ }^{22,23}$ In this study, pretransplant PRA level was found to have no value in predicting either the antibody-mediated rejection or C4d deposition on peritubular capillaries. Statistically significant correlation $(\mathrm{p}<$ 0.05 ) was found between the higher degree ( $>50$ percent) of HLA mismatches and the chances of getting humoral or antibody-mediated rejection as well as the higher grade of rejection.

\section{CONCLUSION}

It is very difficult to evaluate the clinical outcome as well as the graft survival by measurement of pre-transplant Donor Specific Antibody (DSA) level alone. There are chances of shedding antibodies from the graft endothelial cell surface, which results in detection of DSA by commonly available techniques difficult. So the combination of post-transplant DSA with HLA mismatch typing can be used as better graft monitoring investigation. Pre-transplant DSA level does not predict the possibility of upcoming humoral graft rejection.

\section{REFERENCES}

1. Collins AB, Schneeberger EE, Pascual MA, et al. Complement activation in acute humoral renal allograft rejection: diagnostic significance of $\mathrm{C} 4 \mathrm{~d}$ deposits in peritubular capillaries. J Am Soc Nephrol 1999;10(10):2208-14.

2. Halloran PF, Schlaut J, Solez K, et al. The significance of the anti-class I antibody response. II. Clinical and pathologic features of renal transplants with anti-class I like antibody. Transplantation 1992;53(3):550-5.

3. Russ GR, Nicholls C, Sheldon A, et al. Positive B lymphocyte cross match and glomerular rejection in renal transplant recipients. Transplant Proc 1987;19(1 Pt 1):785-8.

4. Yard BA, Spruyt-Gerritse M, Class F, et al. The clinical significance of allospecific antibodies against endothelial cells detected with an antibody-dependent cellular cytotoxicity assay for vascular rejection and graft loss after renal transplantation. Transplantation 1993;55(6):128793.

5. Szulman AE. The histological distribution of blood group substances in man as disclosed by immunofluorescence II. The $\mathrm{H}$ antigen and its relation to $\mathrm{A}$ and $\mathrm{B}$ antigens. J Exp Med 1962;115(5):977-96.

6. Stiller CR, Sinclair NR, Abrahams S, et al. Lymphocytedependent antibody and renal graft rejection. Lancet 1975;1(7913):953-4.

7. Zachary AA, Vega RM, Lucas DP, et al. HLA antibody detection and characterization by solid phase immunoassays: methods and pitfalls. Methods Mol Biol 2012;882:289-308.

8. Zachary AA, Ratner LE, Graziani JA, et al. Characterization of HLA class I specific antibodies by ELISA using solubilized antigen targets: II. Clinical relevance. Hum Immunol 2001;62(3):236-46.

9. Rosenberg SA. The immunotherapy of solid cancers based on cloning the genes encoding tumor-rejection antigens. Annu Rev Med 1996;47:481-91.

10. Mauiyyedi S, Crespo M, Collins AB, et al. Acute humoral rejection in kidney transplantation: II. Morphology, immunopathology and pathologic classification. J Am Soc Nephrol 2002;13(3):779-87. 


\section{Jemds.com}

11. Racusen LC, Colvin RB, Solez K, et al. Antibody-mediated rejection criteria an addition to the banff 97 classification of renal allograft rejection. Am J Transplant 2003;3(6):708-14.

12. Cecka JM. The OPTN/UNOS renal transplant registry. Clin Transplant 2004:1-16.

13. Paul LC. Chronic allograft nephropathy: an update. Kidney Int 1999;56(3):783-93.

14. Anderson CB, Ladefoged SD, Larsen S. Acute kidney graft rejection. A morphological and immunohistological study on zero-hour and follow up biopsies with special emphasis on cellular infiltrates and adhesion molecules. APMIS 1994;102(1):23-37.

15. Feucht HE, Felber E, Gokel MJ, et al. Vascular deposition of complement split products in kidney allografts with cell mediated rejection. Clin Exp Immunol 1991;86(3):464-70.

16. Feucht HE, Schneeberger H, Hillebrand G, et al. Capillary deposition of C4d complement fragment and early renal graft loss. Kidney Int 1993;43(6):1333-8.

17. Prodinger WM. Complement. In: Paul WE. Fundamentals in immunology. Philadelphia: Lippincott Williams \& Wilkins 2003:1077-103.

\section{Original Research Article}

18. Schreuder GM. HLA dictionary 2004: summary of HLA-A, $\mathrm{B},-\mathrm{C},-\mathrm{DRB} 1 / 3 / 4 / 5$, -DQB1alleles and their association with serologically defi ned HLA-A, -B, -C, -DR, and -DQ antigens. Hum Immunol 2005;66(2):170-210.

19. Robinson J, Waller MJ, Parham P, et al. IMGT/HLA and IMGT/MHC: sequence databases for the study of the major histocompatibility complex. Nucleic Acids Res 2003;31(1):311-4.

20. Claas FH, Witvliet MD, Duquesnoy RJ, et al. The acceptable mismatch program as a fast tool for highly sensitized patients awaiting a cadaveric kidney transplantation: short waiting time and excellent graft outcome. Transplantation 2004;78(2):190-3.

21. Duquesnoy RJ, Claas FH. Is the application of HLA matchmaker relevant in kidney transplantation? Transplantation 2005;79(2):250-1.

22. Herzenberg AM, Gill JS, Djurdjev 0, et al. C4d deposition in acute rejection: an independent long term prognostic factor. J Am Soc Nephrol 2002;13(1):234-41.

23. Regele $\mathrm{H}$, Exner $\mathrm{M}$, Watschinger $\mathrm{B}$, et al. Endothelial $\mathrm{C} 4 \mathrm{~d}$ deposition is associated with inferior kidney allograft outcome independently of cellular rejection. Nephrol Dial Transplant 2001;16(10):2058-66. 